\title{
The Perinatal Outcomes by Gestational Weight Gain Range at 30 Weeks of Gestation Among Pre- Pregnancy Underweight Women: A Retrospective Study
}

Takeshi Nagao ( $\sim$ takeshi.n.900113@gmail.com )

St. Luke's International Hospital

Sho Fukui

St. Luke's International Hospital

Sachiko Ohde

St. Luke's International University

Michiko Yamanaka

St. Luke's International Hospital

\section{Research Article}

Keywords: hypertensive disorders of pregnancy, optimal gestational weight gain, preterm birth, small for gestational age, underweight women

Posted Date: June 25th, 2021

DOI: https://doi.org/10.21203/rs.3.rs-601881/v1

License: (c) (1) This work is licensed under a Creative Commons Attribution 4.0 International License.

Read Full License 


\section{Abstract}

Background: The antenatal weight targets of gestational weight gain (GWG) (earlier than 40 weeks) among underweight pregnant women (UPW: pre-pregnancy body mass index $\leq 18.5 \mathrm{~kg} / \mathrm{m}^{2}$ ) that are useful for the management of weight during pregnancy have not been reported. It had been recently pointed out that firm GWG restrictions have led to an increase in the number of low-birth-weight infants in Japan. Thus, this study aimed to evaluate the perinatal outcomes by GWG at 30 weeks of gestation among UPW and to discuss the effects of GWG restrictions.

Methods: This retrospective cohort study was conducted at a hospital in Japan from 2003 to 2020. The UPW $(n=3,643)$ were divided into the four quartile groups based on the GWG at 30 weeks of gestation: group $A \leq 5.7 \mathrm{~kg}, 5.7 \mathrm{~kg}<$ group $B \leq 7.2 \mathrm{~kg}, 7.2 \mathrm{~kg}<$ group $C \leq 8.8 \mathrm{~kg}$, and $8.8 \mathrm{~kg}<$ group D. Their clinical characteristics and outcomes were compared using t-test, chi-square test, and multivariate logistic regression analysis.

Results: The incidence rates of preterm births were 7.5\% $(n=70), 5.0 \%(n=45), 5.4 \%(n=50)$, and $4.9 \%$ $(n=44)$ and the birth rates of small-for-gestational age (SGA) infants were 15.7\% ( $n=147), 9.6 \%(n=87)$, $6.9 \%(n=64)$, and $5.9 \%(n=53)$ in groups $A, B, C$, and $D$, respectively. Multivariate logistic regression analysis showed that group A was significantly associated with preterm births [adjusted odds ratio (Adj. $O R)=1.6 ; 95 \%$ confidence interval $(C l)=1.0-2.3 ; p=0.018]$, and groups $A$ and $B$ were significantly associated with SGA [Adj. OR = 3.0; $95 \% \mathrm{Cl}=2.2-4.2 ; \mathrm{p}<0.001$ ] [Adj. $\mathrm{OR}=1.7 ; 95 \% \mathrm{Cl}=1.2-2.5 ; \mathrm{p}=$ 0.002]. No significant differences were noted in the ratio of cesarean section (CS) $(p=0.344)$, hypertensive disorders of pregnancy (HDP) $(p=0.954)$, and macrosomia $(p=0.147)$ among the four groups.

Conclusions: The GWG at 30 weeks of $>5.7 \mathrm{~kg}$ for preterm birth and $>7.2 \mathrm{~kg}$ for SGA is recommended. Firm weight restrictions for UPW may have led to an increase of adverse outcomes without reducing the risk of CS, HDP, and macrosomia.

\section{Background}

Optimal gestational weight gain (GWG) depends on the pre-pregnancy body mass index (BMI). ${ }^{1,2}$ Some studies have reported that poor GWG and pre-pregnancy underweight were associated with preterm births and delivery of small-for-gestational age (SGA) neonates. ${ }^{3}$ Firm GWG restrictions in Japan have long been placed to prevent perinatal adverse outcomes, such as preeclampsia. The Japan Society of Obstetrics and Gynecology guidelines recommend an optimal GWG of 9-12 kg at 40 weeks of gestation for underweight pregnant women (UPW) compared with a weight gain of 12.7-18.1 kg specified by the Institute of Medicine. ${ }^{4,5}$

It had been recently pointed out that firm GWG restrictions have led to an increase in the number of lowbirth-weight (LBW) infants in Japan. ${ }^{6}$ In fact, the birth rates of LBW neonates are significantly higher in 
Japan than in the rest of the world, and this rate is constantly increasing. ${ }^{7}$ The incidence of LBW infants in Japan was $5.2 \%$ in 1980 , and this escalated to $9.4 \%$ in 2019 against the average percentage of LBW infants of $6.6 \%$ stated by the Organisation for Economic Co-operation and Development member countries. ${ }^{8}$

Data on the appropriate GWG range among UPW are limited. Furthermore, previous studies have represented optimal GWG as the estimated weight gain at 40 weeks of gestation or the weight gain per week. However, the antenatal weight targets of GWG (earlier than 40 weeks) among UPW that are useful for the management of maternal weight during pregnancy have not been reported.

Therefore, this retrospective cohort study aimed to evaluate the perinatal outcomes by GWG range, determine the appropriate weight gain range at 30 weeks of gestation among UPW, and discuss the effects of firm GWG restrictions in Japan.

\section{Methods}

\section{Participants}

We conducted a retrospective cohort study at St. Luke's International Hospital (Tokyo, Japan), an acutecare tertiary-level hospital with 520 beds, from July 22, 2003 to April 30, 2020. Underweight women (prepregnancy $\mathrm{BMI} \leq 18.5 \mathrm{~kg} / \mathrm{m}^{2}$ ) who gave birth at St. Luke's International Hospital during the study period were screened. Multifetal gestations, stillbirth, non-Japanese participants, or pregnant women who delivered before 30 weeks of gestation were excluded. Participants were divided into four groups based on the quartile ranges of GWG at 30 weeks of gestation: group $A \leq 5.7 \mathrm{~kg}, 5.7 \mathrm{~kg}<$ group B $\leq 7.2 \mathrm{~kg}, 7.2$ $\mathrm{kg}<$ group $\mathrm{C} \leq 8.8 \mathrm{~kg}$, and $8.8 \mathrm{~kg}<$ group $\mathrm{D}$. The association between clinical characteristics in each group and outcomes were investigated.

The primary outcomes were incidence rates of preterm births (before 37 weeks of gestation) and SGA infants, and the secondary outcomes were primary cesarean sections (CS) and maternal and neonatal complications. Maternal complications included hypertensive disorders of pregnancy (HDP), gestational diabetes mellitus (GDM), intrapartum hemorrhage (CS $>1,000 \mathrm{~mL}$, vaginal delivery $>500 \mathrm{~mL}$ ), and postterm delivery ( $\geq 42$ weeks of gestation). Neonatal complications included neonatal asphyxia (5-min Apgar score $<7)$, macrosomia $(>4,000 \mathrm{~g})$, and need for neonatal intensive care.

\section{Definition}

The variables extracted were age, BMI, nulliparity, advanced maternal age ( $\geq 35$ years), smoking history (during and/or prior to pregnancy), use of assisted reproductive therapy (ART), and presence of hyperemesis and anemia (hemoglobin $<11.0 \mathrm{mg} / \mathrm{dL}$ during the first trimester).

We defined SGA infant as a newborn with birth weight and height that were below the 10th percentile for all newborns of the same gestational age, according to statistics from the Japan Pediatric Society. 


\section{Statistical analyses}

The patient characteristics and pregnancy outcomes between the four quartile groups were compared using the chi-square test and one-way analysis of variance with Bonferroni correction as a multiple comparison procedure in the univariate analysis. Multivariate logistic regression analysis was performed to identify risk factors for SGA and preterm births. In the multivariate logistic regression analysis, GWG was included in the independent variables as an exploratory item, and nulliparity, advanced maternal age, smoking history, ART, hyperemesis, and anemia were also included with the forced entry method based on previous reports. ${ }^{9,10}$

All statistical hypothesis tests were performed at $5 \%$ significance level. Analyses were performed using SPSS version $19.0 \mathrm{~J}$ (IBM Japan, Tokyo, Japan).

\section{Results}

Of 18,430 women who delivered after 22 weeks of gestation at our hospital during the study period, 4,159 were underweight (pre-pregnancy BMl $<18.5 \mathrm{~kg} / \mathrm{m}^{2}$ ). A total of 74 multifetal pregnancies, 60 stillbirths, 152 women of non-Japanese ethnicity, 24 pregnant women who delivered before 30 weeks of pregnancy, and 206 women with missing data were excluded. Therefore, 3,643 UPW were included in this study (Additional File 1). They were divided into four groups based on the quartile ranges of GWG at 30 weeks of gestation. There were 933 (25.6\%) women in group A, 899 (24.6\%) women in group B, 920 (25.2\%) women in group C, and 891 (24.4\%) women in group D.

\section{Participant characteristics}

The baseline characteristics of the four quartile groups are visible in Table 1. In the univariate analysis, age $(p=0.013)$, advanced maternal age $(p=0.021)$, smoking history $(p<0.001)$, ART $(p<0.001)$, and anemia during the first trimester $(p=0.048)$ were statistically significant in the four quartile groups. 
Table 1

Baseline characteristics of the four quartile groups based on gestational weight gain at 30 weeks of gestation

\begin{tabular}{|llllll|}
\hline Variable & $\begin{array}{l}\text { Group A } \\
\mathbf{n = 9 3 3}\end{array}$ & $\begin{array}{l}\text { Group B } \\
\mathbf{n = 8 9 9}\end{array}$ & $\begin{array}{l}\text { Group C } \\
\mathbf{n = 9 2 0}\end{array}$ & $\begin{array}{l}\text { Group D } \\
\mathbf{n = 8 9 1}\end{array}$ & p-value \\
\hline Age, mean (SD) & $34.0(4.5)$ & $34.1(4.3)$ & $33.8(4.3)$ & $33.5(4.5)$ & $\mathbf{0 . 0 1 3}$ \\
\hline BMl, mean (SD) & $17.6(0.6)$ & $17.6(0.7)$ & $17.6(0.7)$ & $17.6(0.7)$ & 0.509 \\
\hline Nulliparous, $\mathrm{n}(\%)$ & $644(69.0)$ & $619(68.8)$ & $621(67.5)$ & $603(67.6)$ & 0.853 \\
\hline Advanced maternal age, $\mathrm{n}(\%)$ & $426(45.6)$ & $429(47.7)$ & $407(44.2)$ & $362(40.6)$ & 0.021 \\
\hline Smoking history, $\mathrm{n}(\%)$ & $39(4.1)$ & $30(3.3)$ & $50(5.4)$ & $75(8.4)$ & $<0.001$ \\
\hline ART, $\mathrm{n}(\%)$ & $107(11.4)$ & $106(11.7)$ & $70(7.6)$ & $61(6.8)$ & $<0.001$ \\
\hline Hyperemesis, $\mathrm{n}(\%)$ & $36(3.8)$ & $39(4.3)$ & $28(3.0)$ & $24(2.6)$ & 0.210 \\
\hline Anemia, $\mathrm{n}(\%)$ & $146(15.6)$ & $112(12.4)$ & $108(11.7)$ & $108(12.1)$ & $\mathbf{0 . 0 4 8}$ \\
\hline BMI, body mass index; ART, assisted reproductive therapy. & & & \\
\hline
\end{tabular}

\section{Primary outcomes}

The incidence of preterm births was numerically higher in the Group A (7.5\%) than in Groups B (5.0\%), C $(5.4 \%)$, and $D(4.9 \%)$, while the difference was not statistically significant $(p=0.058)$. As regards the incidence of SGA infants, 147 (15.7\%) women in group A, 87 (9.6\%) in group B, 64 (6.9\%) in group C, and $53(5.9 \%)$ in group D delivered SGA infants. A univariate analysis revealed that the delivery of SGA infants was statistically significant in the four groups $(p<0.001)$. The proportions of underweight women who delivered preterm and SGA infants in the four quartile groups are visible in Figs. 1 and 2, respectively. In the univariate analysis using Bonferroni correction as a multiple comparison procedure, a significant association for the delivery of SGA infants was identified between groups $A$ and $B(p<0.001)$, groups $A$ and $C(p<0.001)$, groups $A$ and $D(p<0.001)$, and groups $B$ and $D(p=0.003)$.

Nulliparity, advanced maternal age, smoking history, ART, hyperemesis, and anemia were included in the multivariate model. A multivariate analysis revealed that group A was significantly associated with preterm births (adjusted odds ratio [adj. OR] $=1.6 ; 95 \%$ confidence interval $[\mathrm{Cl}]=1.0-2.3 ; \mathrm{p}=0.018$ ) (Table 2). Another multivariate analysis also revealed that group A (adj. OR $=3.0 ; 95 \% \mathrm{Cl}=2.2-4.2 ; \mathrm{p}<$ $0.001)$, group $B(\operatorname{adj} . O R=1.7 ; 95 \% \mathrm{Cl}=1.2-2.5 ; p=0.002)$, nulliparity $(\operatorname{adj} . \mathrm{OR}=0.7 ; 95 \% \mathrm{Cl}=0.5-0.9 ; \mathrm{p}=$ $0.015)$, and $A R T(\operatorname{adj} . \mathrm{OR}=0.6 ; 95 \% \mathrm{Cl}=0.4-0.9 ; \mathrm{p}=0.049)$ were significantly associated with the delivery of SGA infants (Table 2). 
Table 2

Results of multivariate logistic regression analysis for the association between gestational weight gain at 30 weeks of gestation and primary outcomes: preterm births and small-for-gestational age infants

\begin{tabular}{|lllllll|}
\hline & Preterm births & & \multicolumn{3}{c|}{ Small-for-gestational age infants } \\
\hline & Adjusted OR & $95 \%$ Cl & p-value & Adjusted OR & $95 \%$ Cl & p-value \\
\hline Group A $(\leq 5.7 \mathrm{~kg})$ & 1.6 & $1.0-2.3$ & 0.018 & 3.0 & $2.2-4.2$ & $<0.001$ \\
\hline Group B $(\leq 7.2 \mathrm{~kg})$ & 1.0 & $0.6-1.5$ & 0.870 & 1.7 & $1.2-2.5$ & 0.002 \\
\hline Group C $(\leq 8.8 \mathrm{~kg})$ & 1.1 & $0.7-1.6$ & 0.624 & 1.1 & $0.8-1.7$ & 0.347 \\
\hline Group D $(<8.8 \mathrm{~kg})$ & Ref & Ref & Ref & Ref & Ref & Ref \\
\hline Nulliparity & 0.7 & $0.5-1.0$ & 0.082 & 0.7 & $0.5-0.9$ & 0.015 \\
\hline Advanced maternal age & 1.3 & $0.9-1.7$ & 0.066 & 0.9 & $0.7-1.2$ & 0.687 \\
\hline Smoking history & 1.3 & $0.7-2.3$ & 0.353 & 1.3 & $0.8-2.1$ & 0.214 \\
\hline ART & 0.8 & $0.5-1.4$ & 0.604 & 0.6 & $0.4-0.9$ & 0.049 \\
\hline Hyperemesis & 0.2 & $0.0-1.0$ & 0.055 & 1.1 & $0.6-1.9$ & 0.697 \\
\hline Anemia & 0.7 & $0.4-1.2$ & 0.261 & 1.0 & $0.7-1.4$ & 0.899 \\
\hline ART, assisted reproductive therapy. & & & & & \\
\hline
\end{tabular}

\section{Secondary outcomes}

A univariate analysis of the secondary outcomes revealed that the GWG at 30 weeks was significantly associated with the incidence of GDM $(p<0.001)$, intrapartum hemorrhage $(p=0.018)$, post-term delivery $(p=0.016)$, and need for neonatal intensive care $(p<0.001)$. No significant differences in primary CS $(p=$ $0.344), \operatorname{HDP}(p=0.954)$, and macrosomia $(p=0.147)$ were noted among the four quartile groups (Table 3). 
Table 3

Four quartile groups based on gestational weight gain at 30 weeks of gestation and secondary outcomes: primary cesarean section, maternal complications, and neonatal complications

\begin{tabular}{|c|c|c|c|c|c|}
\hline & $\begin{array}{l}\text { Group A } \\
(n=933)\end{array}$ & $\begin{array}{l}\text { Group B } \\
(n=899)\end{array}$ & $\begin{array}{l}\text { Group C } \\
(n=920)\end{array}$ & $\begin{array}{l}\text { Group D } \\
(n=891)\end{array}$ & $\mathrm{p}$-value \\
\hline Primary cesarean section, n (\%) & $96(10.2)$ & $117(13.0)$ & $106(11.5)$ & $103(11.5)$ & 0.344 \\
\hline \multicolumn{6}{|l|}{ Maternal complications } \\
\hline HDP, n (\%) & $30(3.2)$ & $32(3.5)$ & $29(3.1)$ & $28(3.1)$ & 0.954 \\
\hline GDM, n (\%) & $72(7.7)$ & $49(5.4)$ & $41(4.4)$ & $25(2.8)$ & $<0.001$ \\
\hline Intrapartum hemorrhage, n (\%) & $166(17.7)$ & $171(19.0)$ & $169(18.3)$ & $206(23.1)$ & 0.018 \\
\hline Post-term delivery, n (\%) & $1(0.1)$ & $1(0.1)$ & $7(0.7)$ & $8(0.8)$ & 0.016 \\
\hline \multicolumn{6}{|l|}{ Neonatal complications } \\
\hline Neonatal intensive care, n (\%) & $102(10.9)$ & $66(7.3)$ & $55(5.9)$ & $63(7.0)$ & $<0.001$ \\
\hline Neonatal asphyxia, n (\%) & $8(0.8)$ & $6(0.6)$ & $7(0.7)$ & $5(0.5)$ & 0.892 \\
\hline Macrosomia, n (\%) & $2(0.2)$ & $0(0.0)$ & $3(0.3)$ & $5(0.5)$ & 0.147 \\
\hline
\end{tabular}

\section{Discussion}

In this study, a GWG of $\leq 5.7 \mathrm{~kg}$ at 30 weeks of gestation significantly increased the incidence of preterm births. Additionally, a GWG of $\leq 7.2 \mathrm{~kg}$ significantly increased the rate of delivery of SGA infants among Japanese UPW. The level of neonatal intensive care was also higher when the GWG at 30 weeks of gestation was $\leq 5.7 \mathrm{~kg}$. Adverse outcomes that are known to increase with excessive GWG, such as CS, HDP, and macrosomia, revealed no statistically significant increases with weight gain. Contrary to the findings of previous studies, the proportion of GDM decreased with more GWG. These results suggested that firm weight restrictions for UPW may have led to an increase in the incidence of adverse pregnancy outcomes without reducing the risk of CS, HDP, GDM, and macrosomia.

This study demonstrated that adequate weight gain in UPW can reduce the rate of preterm births and delivery of SGA infants. A low pre-pregnancy BMI is, in itself, a risk factor for preterm births. ${ }^{11}$ However, in this study, the preterm birth rate was the highest in group $A$, while the rates in groups $B, C$, and $D$ were similar to the Japanese average preterm birth rate (approximately $5.7 \%$ since 2000 ). ${ }^{7}$ This suggests that even if pre-pregnancy BMI is underweight, appropriate GWG can prevent preterm births. In the present study, the higher the maternal weight gain, the lower the proportion of SGA. According to the Developmental Origins of Health and Disease theory, LBW infants have higher risks of future academic 
deficits, type 2 DM, and cardiovascular disease. ${ }^{12-14}$ Therefore, the firm weight restriction for Japanese UPW can increase not only the incidence of birth rate of SGA neonates but also those of future diseases.

To the best of our knowledge, this is the first study to evaluate the association between antenatal maternal weight (not estimated weight at 40 weeks) and perinatal adverse outcomes among Japanese UPW. Based on our analysis, a GWG of $>5.7 \mathrm{~kg}$ at 30 weeks is recommended to prevent preterm births, and a weight gain of $>7.2 \mathrm{~kg}$ is required to reduce the rate of SGA infants. Pregnant women are advised to manage their own weight during pregnancy, and clinicians should monitor pregnant women's weight at every prenatal visit. ${ }^{15}$ In most previous studies, the optimal GWG refers to the predicted estimated weight gain at 40 weeks or the weight gain per week. ${ }^{16}$ These studies were epidemiological studies using perinatal databases that included only the maternal weight data at the time of delivery, not the maternal weight data during pregnancy. The antenatal weight targets from our results are more useful for pregnant women to manage their own weight and prevent preterm births and reduce the rate of delivery of SGA neonates.

This study has some limitations. First, although all weights during pregnancy were measured using the same weighing scale, pre-pregnancy weight was based on self-reported weights. Second, as this was an observational study, we did not evaluate the methods of intervention. Therefore, it remains unclear if the mode of gaining weight (e.g., through diet) reduces perinatal adverse outcomes, such as preterm births and delivery of SGA neonates. Regardless of stern weight gain restrictions, underweight women may be less likely to gain weight during pregnancy. Furthermore, the proportion of underweight women in the younger population has increased in Japan. In 2017, 21.7\% of Japanese women of reproductive age were underweight compared with $13.4 \%$ in $1981 .{ }^{17}$ Thus, preconception counseling is required, as well as education and awareness before pregnancy, as this would help pregnant women achieve an appropriate BMI.

In conclusion, a GWG of $>5.7 \mathrm{~kg}$ at 30 weeks is recommended to prevent preterm births and a weight gain of $>7.2 \mathrm{~kg}$ is required to reduce the rate of SGA neonates. Firm weight restrictions for UPW may have led to an increase in the incidence of adverse pregnancy outcomes without reducing the risk of CS, HDP, GDM, and macrosomia. Therefore, it is critical to revise the optimal antenatal weight gain range based on this study.

\section{Abbreviations}

GWG

gestational weight gain

SGA

small-for-gestational age

UPW

underweight pregnant women

LBW 
low birth weight

CS

cesarean section

HDP

hypertensive disorders of pregnancy

GDM

gestational diabetes mellitus

ART

assisted reproductive therapy

\section{Declarations}

\section{Ethics approval and consent to participate}

This study was approved by the St. Luke's International Hospital Research Ethics Committee institutional review board (approval no. 20-R162). Since this study does not reveal or contain any individual's personal data, the need to obtain informed consent was waived by St. Luke's International Hospital Research Ethics Committee. The study was performed in accordance with the ethical standards of the Declaration of Helsinki (1964) and its subsequent amendments.

Consent for publication Not applicable

\section{Availability of data and materials}

All authors shared the raw data. The datasets used and/or analysed during the current study available from the corresponding author on reasonable request.

\section{Competing interests}

The authors have no conflicts of interest to disclose.

\section{Funding}

Not applicable

Authors' contributions TN, SF and SO designed the research study. SF and SO analysed the data. TN wrote the manuscript. MY provided advice and proofread the manuscript. All the authors approved the final version of the manuscript.

Acknowledgment Not applicable

\section{References}


1. Cedergren MI. Optimal gestational weight gain for body mass index categories. Obstet Gynecol. 2007;110:759-64.

2. Goldstein RF, Abell SK, Ranasinha S, Misso M, Boyle JA, Black HB, et al. Association of gestational weight gain with maternal and infant outcomes: a systematic review and meta-analysis. JAMA. 2017;317:2207-25.

3. Ehrenberg HM, Dierker L, Milluzzi C, Mercer BM. Low maternal weight, failure to thrive in pregnancy, and adverse pregnancy outcomes. Am J Obstet Gynecol. 2003;189:1726-30.

4. The Japan Society of Obstetrics and Gynecology. Guideline for obstetrical practice in Japan; 2020.

5. Rasmussen KM, Yaktine AL, editors. Weight Gain During Pregnancy: Reexamining the Guidelines. Washington (DC): The National Academies Press; 2009.

6. Normile D. Staying slim during pregnancy carries a price. Science. 2018;361:440.

7. Statistics and Information Department. Vital Statistics. Tokyo, Japan: Ministry of Health, Labour, and Welfare. 2019. URL. Accessed DATE MONTH YEAR.

8. OECD. Infant Health: Low Birth Weight. Health at a Glance 2015: OECD Indicators. Paris, France: OECD Publishing; 2015.

9. Kominiarek MA, Saade G, Mele L, Bailit J, Reddy UM, Wapner RJ, et al. Association between gestational weight gain and perinatal outcomes. Obstet Gynecol. 2018;132:875-81.

10. Petry CJ, Ong KK, Beardsall K, Hughes IA, Acerini CL, Dunger DB. Vomiting in pregnancy is associated with a higher risk of low birth weight: a cohort study. BMC Pregnancy Childbirth. 2018;18:133.

11. Jeric M, Roje D, Medic N, Strinic T, Mestrovic Z, Vulic M. Maternal pre-pregnancy underweight and fetal growth in relation to institute of medicine recommendations for gestational weight gain. Early Hum Dev. 2013;89:277-81.

12. Breslau N, Paneth NS, Lucia VC. The lingering academic deficits of low birth weight children. Pediatrics. 2004;114:1035-40.

13. Zanetti D, Tikkanen E, Gustafsson S, Priest JR, Burgess S, Ingelsson E. Birthweight, type 2 diabetes mellitus, and cardiovascular disease: addressing the Barker hypothesis with Mendelian randomization. Circ Genom Precis Med. 2018;11:e002054.

14. Barker DJ, Winter PD, Osmond C, Margetts B, Simmonds SJ. Weight in infancy and death from ischaemic heart disease. Lancet. 1989;2:577-80.

15. Deputy NP, Sharma AJ, Kim SY. Gestational weight gain - United States, 2012 and 2013. MMWR Morb Mortal Wkly Rep. 2015;64:1215-20.

16. Morisaki N, Nagata C, Jwa SC, Sago H, Saito S, Oken E, et al. Pre-pregnancy BMI-specific optimal gestational weight gain for women in Japan. J Epidemiol. 2017;27:492-98.

17. Statistics and Information Department. The National Health and Nutrition Survey in Japan. Tokyo, Japan: Ministry of Health, Labour, and Welfare; 2017. URL. Accessed DATE MONTH YEAR.

\section{Figures}




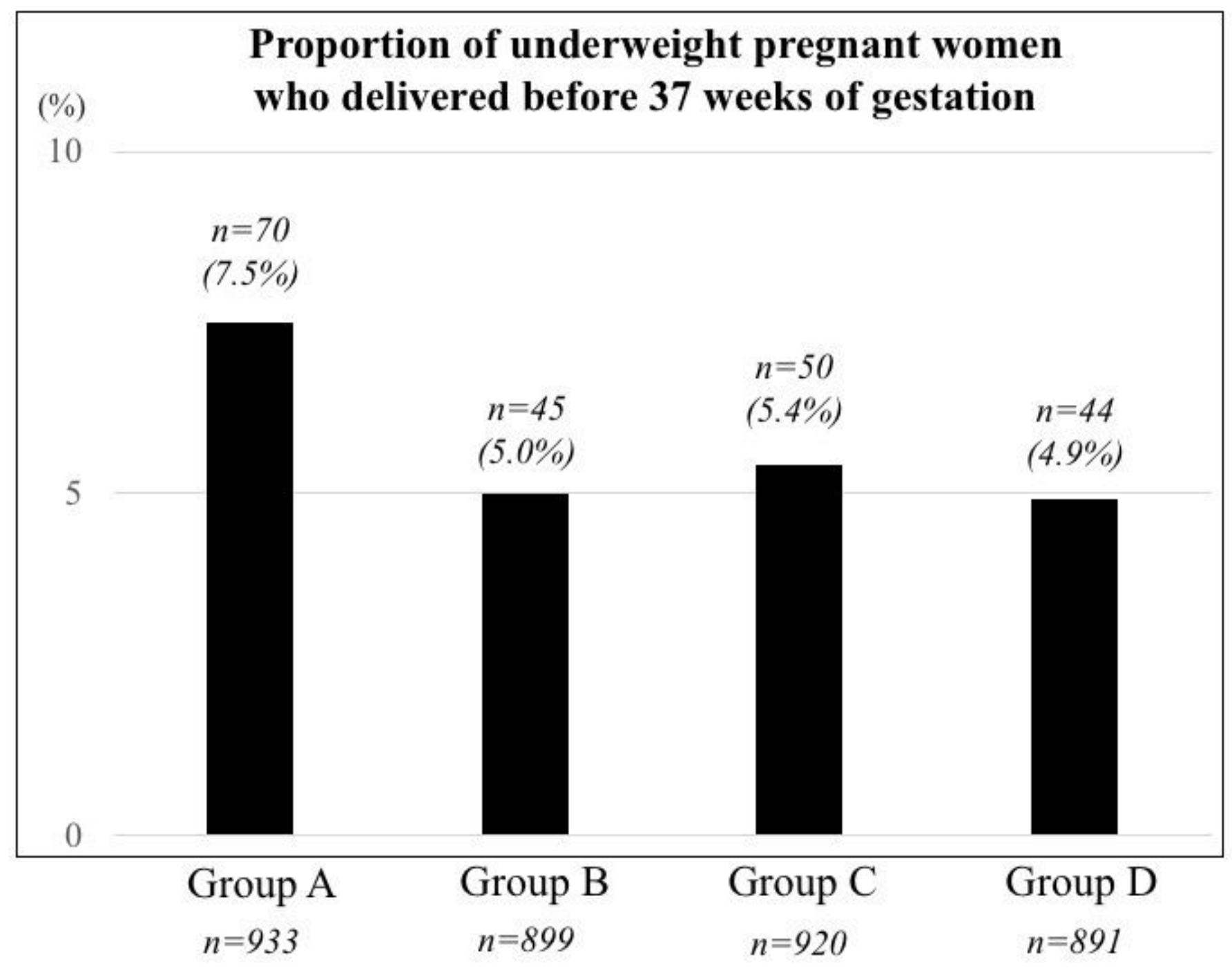

Figure 1

Proportions of underweight women who delivered preterm in the four quartile groups based on gestational weight gain at 30 weeks of gestation 


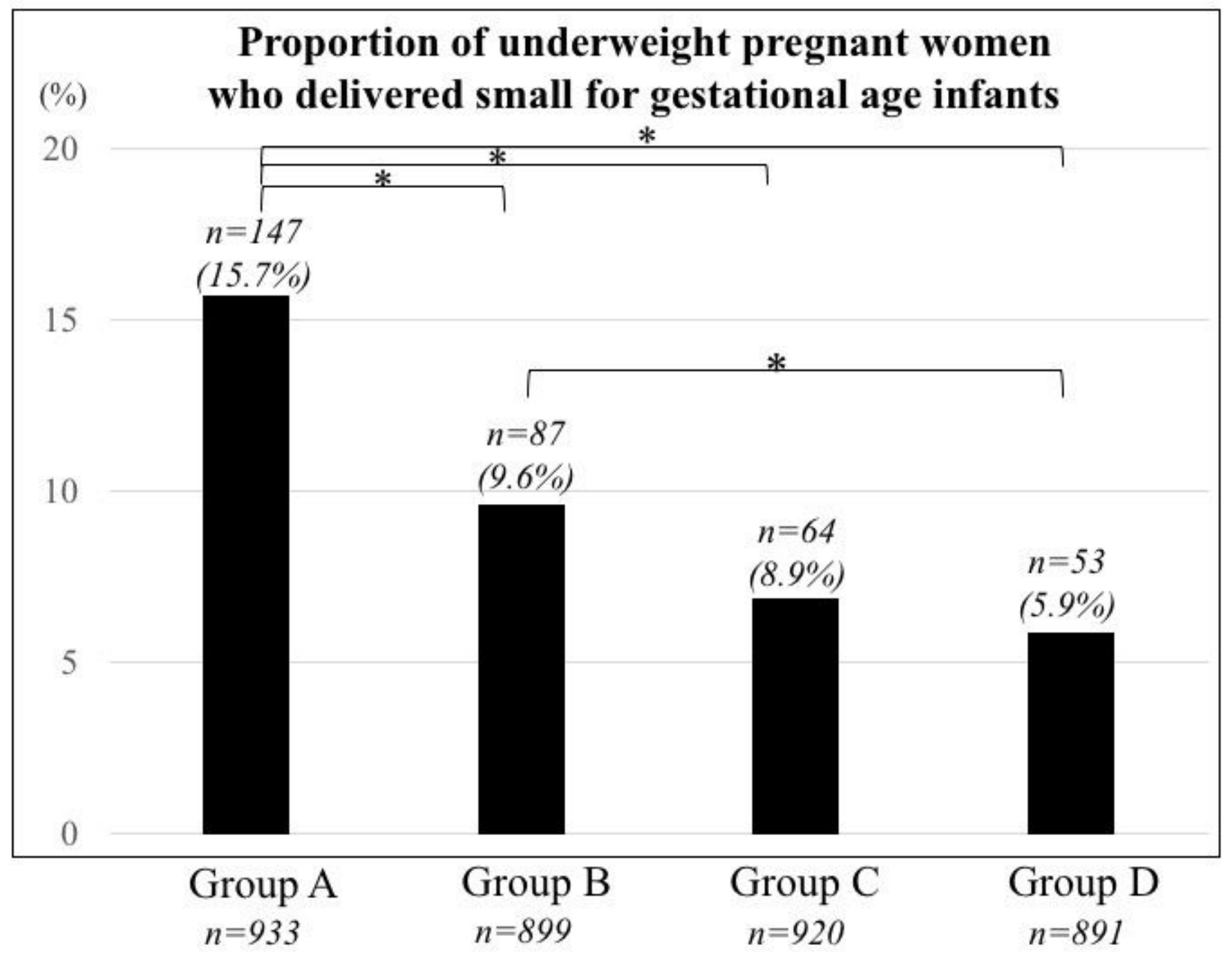

Figure 2

Proportions of underweight women who delivered small-for-gestational age infants in the four quartile

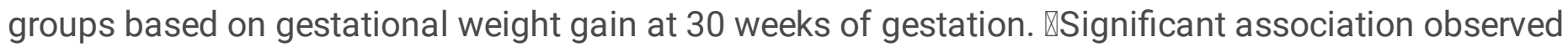
between two groups (Bonferroni correction as a multiple comparison procedure) 


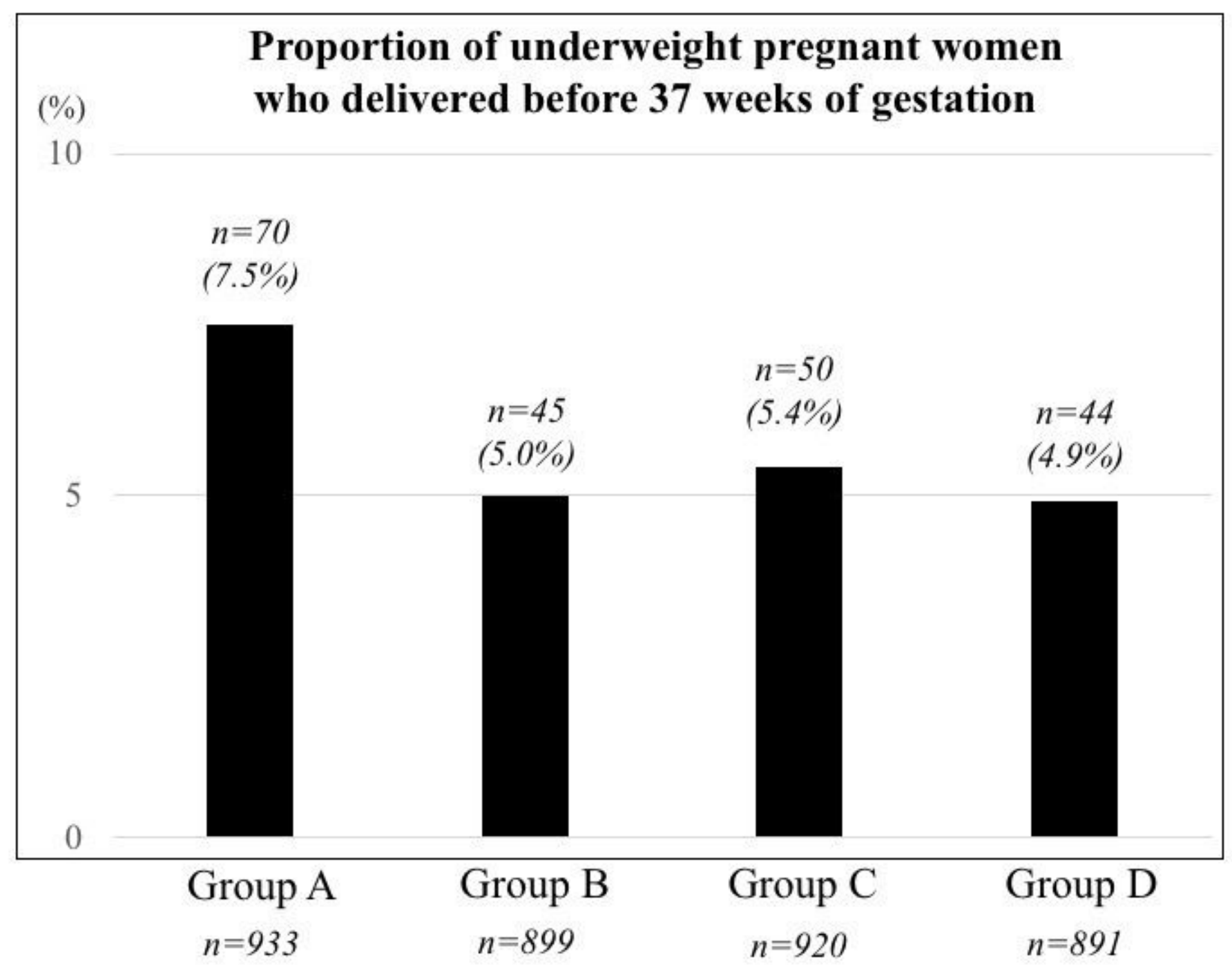

Figure 3

Proportions of underweight women who delivered preterm in the four quartile groups based on gestational weight gain at 30 weeks of gestation 


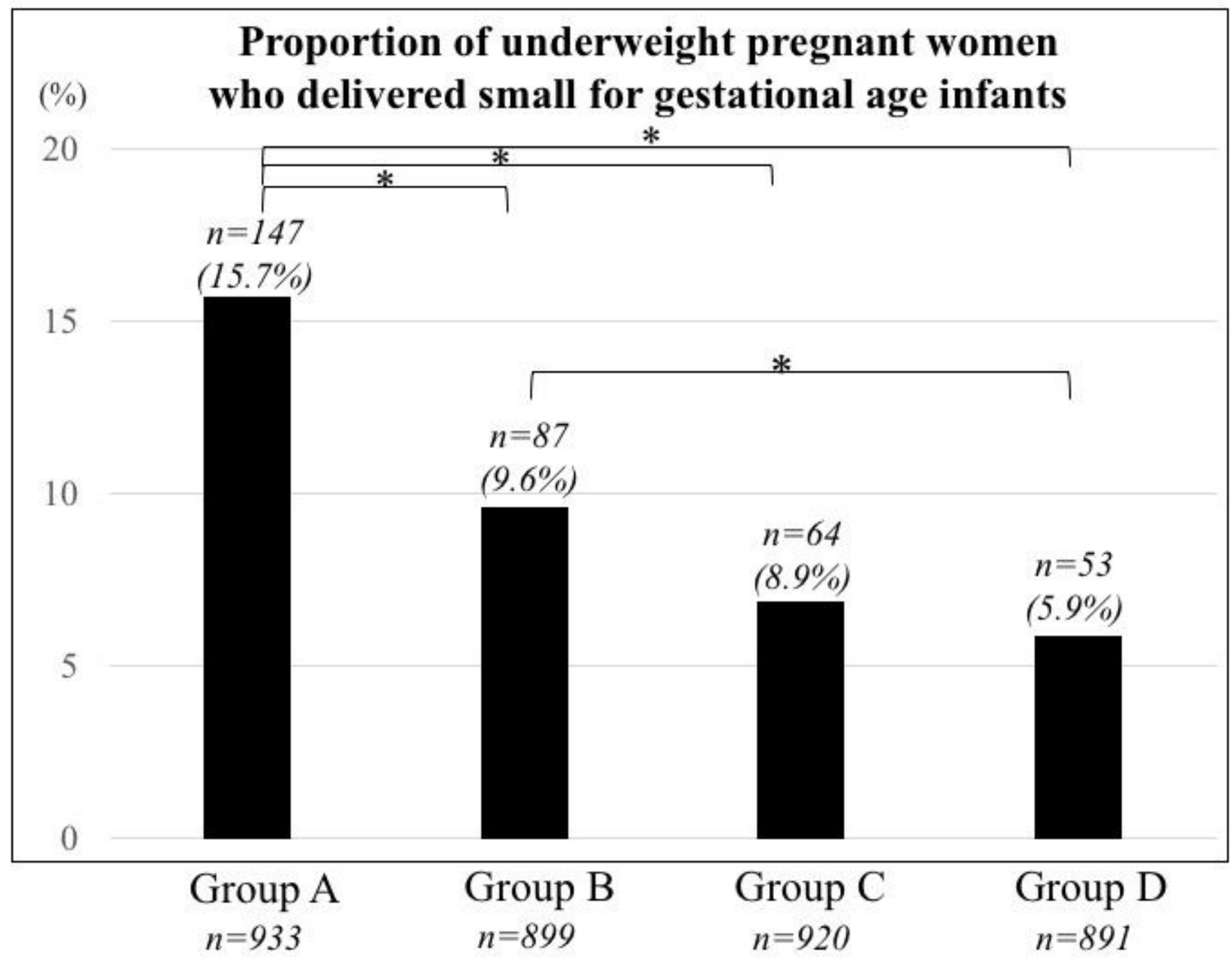

Figure 4

Proportions of underweight women who delivered small-for-gestational age infants in the four quartile

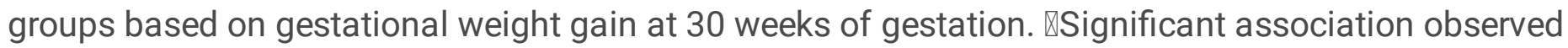
between two groups (Bonferroni correction as a multiple comparison procedure)

\section{Supplementary Files}

This is a list of supplementary files associated with this preprint. Click to download.

- SupplementaryFigure.jpg 